\title{
Education and Poverty: Confronting the Evidence
}

Helen F. Ladd

\begin{abstract}
Current U.S. policy initiatives to improve the U.S. education system, including No Child Left Behind, test-based evaluation of teachers, and the promotion of competition are misguided because they either deny or set to the side a basic body of evidence documenting that students from disadvantaged households on average perform less well in school than those from more advantaged families. Because these policy initiatives do not directly address the educational challenges experienced by disadvantaged students, they have contributed little-and are not likely to contribute much in the future-to raising overall student achievement or to reducing achievement and educational attainment gaps between advantaged and disadvantaged students. Moreover, such policies have the potential to do serious harm. Addressing the educational challenges faced by children from disadvantaged families will require a broader and bolder approach to education policy than the recent efforts to reform schools. (C) 2012 by the Association for Public Policy Analysis and Management.
\end{abstract}

\section{INTRODUCTION}

Evidence-based policymaking. That is the rallying cry for policy researchers like many of us and also for many policymakers, including the Obama administration itself. Providing a forum for researchers to present and discuss policy-relevant research that can provide the evidence needed for better policymaking is one of the major functions of the Association for Public Policy Analysis and Management (APPAM).

Policy-relevant evidence often comes from careful studies of specific policy interventions such as job training or negative income tax programs and is based on random control trials or other forms of rigorous quantitative and qualitative analysis. Many of you in the audience today have made major methodological and substantive contributions through research of this type in a range of policy areas.

I want to focus today on the policy importance of evidence of a broader type-a type that does not require any sophisticated modeling. And I will do so in the context of my main field of policy research, education policy.

Historically this country prided itself on its outstanding education system, which educated a higher proportion of its population to more advanced levels than most other countries. The Sputnik challenge from Russia in the late 1950s and the publication of A Nation at Risk (1983) during the Reagan years, however, highlighted significant concerns about the quality of the U.S. education system. Concerns today are based on average test scores of U.S. students that are middling compared to 


\section{2 / Education and Poverty}

those of other nations, on U.S. graduation rates that once were well above those of most other countries but now have been overtaken by rising rates in other countries, and on abysmal educational attainment and test score performance of many disadvantaged students, especially those in urban centers. These patterns and trends, as well as recent widely publicized documentaries including for example, Waiting for Superman, have convinced many people that our education system is in crisis. ${ }^{1}$

During the decades following A Nation at Risk, U.S. education policymakers responded to the perceived crisis in a variety of ways such as creating ambitious national goals and promoting standards-based reform. Of interest here are the policy initiatives of the past decade, which include school accountability in the form of the federal No Child Left Behind (NCLB) Act, test-based approaches to evaluate teachers, and promotion of expanded parental choice, charter schools, and competition.

I will argue today that these current policy initiatives are misguided because they either deny or set to the side a basic body of evidence documenting that students from disadvantaged households on average perform less well in school than those from more advantaged families. Because they do not directly address the educational challenges experienced by disadvantaged students, these policy strategies have contributed little-and are not likely to contribute much in the future - to raising overall student achievement or to reducing achievement and educational attainment gaps between advantaged and disadvantaged students. Moreover, such policies have the potential to do serious harm.

Addressing the educational challenges faced by children from disadvantaged families will require a broader and bolder approach to education policy than the recent efforts to reform schools. It will also require a more ambitious research agenda, one that APPAM researchers-not just those of us who typically focus our research on education policy, but also researchers in a wide range of social policy issues-are in a good position to advance.

\section{EVIDENCE ON THE RELATIONSHIP BETWEEN FAMILY BACKGROUND AND EDUCATIONAL OUTCOMES}

Study after study has demonstrated that children from disadvantaged households perform less well in school on average than those from more advantaged households. This empirical relationship shows up in studies using observations at the levels of the individual student, the school, the district, the state, the country. The studies use different measures of family socioeconomic status (SES): income-related measures such as family income or poverty; education level of the parents, particularly of the mother; and in some contexts occupation type of the parents or employment status. Studies based on U.S. administrative data often measure SES quite crudely, using eligibility for free and reduced price lunch, for example, as a proxy for low family income, and using student race as a proxy for a variety of hard to measure characteristics. Studies based on longitudinal surveys often include far richer measures of family background. Regardless of the measures used and the sophistication of the methods, similar patterns emerge.

I start with differences in test scores between U.S. students whose families have high and low SES as measured by family income. The best research on income-based achievement gaps appears in a recent study by Sean Reardon for which he compiled test scores for school-aged children and family income from a large number of U.S.based nationally representative surveys over a 55-year period. By standardizing

\footnotetext{
${ }^{1}$ Not everyone agrees that the system is in crisis. See, for example, the critique of this view by Berliner and Biddle (1995).
} 


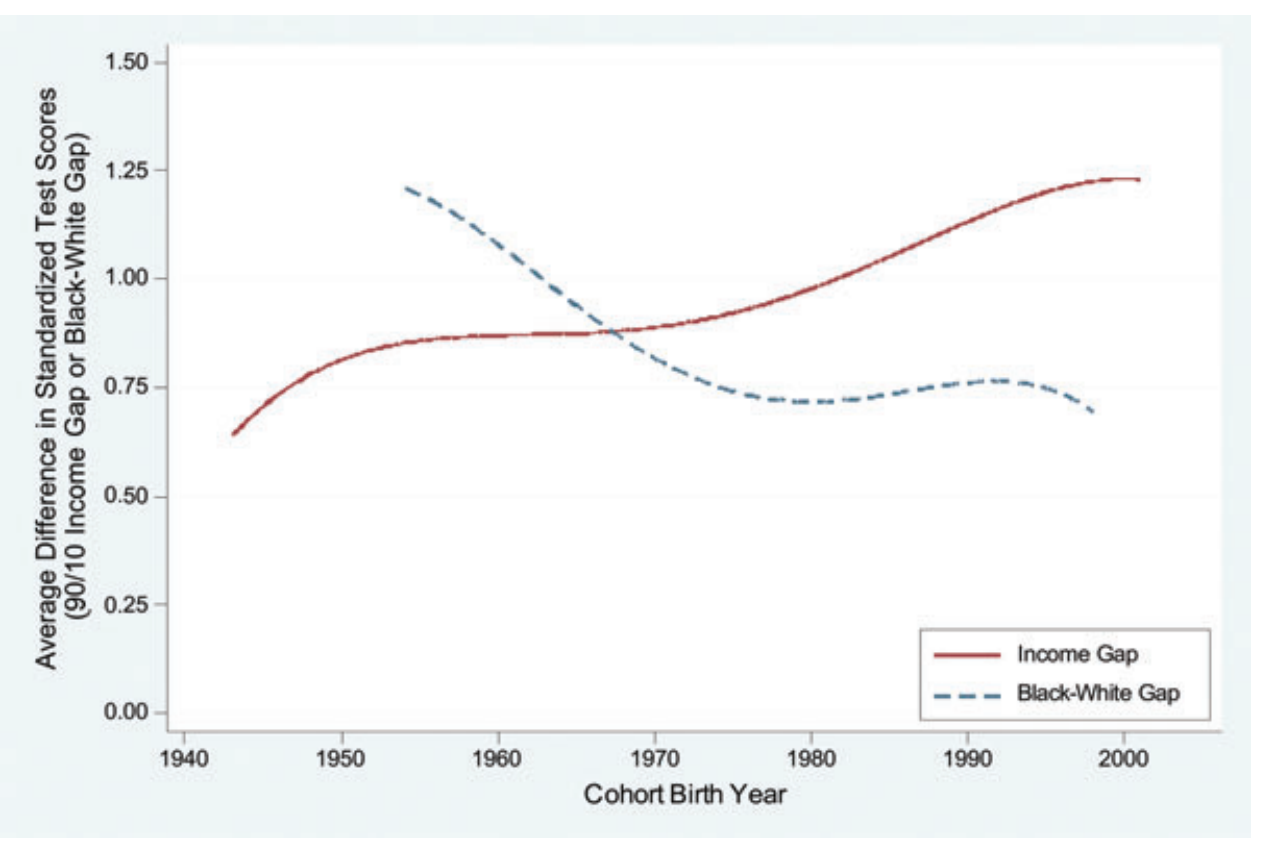

Figure 1. Trends in Income and Black-White Gaps in Reading, 1943 to 2001 Cohorts (Simplified Version of Graph in Reardon, 2011, ch. 5).

income differentials and achievement levels to make them comparable over time, he was able to estimate the trend in reading and math test scores gaps between the children in the 90th and the 10th income percentiles. As shown by the rising line in Figure 1 for reading gaps, the results are striking. The figure shows that, when first measured in the early 1940s, the gap in reading achievement between children from high- and low-income families was about 0.60 standard deviations. It subsequently more than doubled to 1.25 standard deviations by $2000 .^{2}$

These income-based achievement gaps are large. To put them in perspective, consider the black-white test score gap as measured by the National Assessment of Education Progress (NAEP) for 13-year olds, depicted by the dashed line in Figure $1 .^{3}$ That gap was about one standard deviation in the 1970 s, then fell to about 0.50 during the 1980 s where it has remained relatively constant. As a result, the achievement gap between children from high- and low-income families is now far larger than the gap between black and white children.

People can disagree about whether the relationship between family income, or broader measures of SES, on the one hand and educational outcomes on the other is correlational or causal. For example, it may be that factors correlated with low income such as poor child health or single-parent family structures account for

\footnotetext{
${ }^{2}$ Figure 1 is a simplified version of graph 5.3 in Reardon (2011). The trend line is estimated based on the income-based achievement gaps calculated from the 12 nationally representative studies that include data on reading scores for school-age children and information on family income. The fitted regressions line is weighted by the inverse of the sampling variance of each estimate. The figure for math is similar (see Figure 5.4 in Reardon, 2011).

3 The estimated black-white gap trend line is based on all the available black-white gap information that is available in NAEP long-term trends for 13-year olds and main NAEP for eighth graders, with the latter adjusted for age differences. The line can be interpreted at the trend in the gap for 13-year olds. See footnote 6 in Reardon (2011).
} 
the relationship rather than income itself. Further, people may disagree about the extent to which schools and school policies contribute to the low achievement of children from low-SES households. At this point, I simply want to draw attention to the correlation. Later I will say more about the mechanisms through which low SES may translate into low academic performance.

Suffice it to say at this point that research documents a variety of symptoms of low SES that are relevant for children's subsequent educational outcomes. These include, for example, poor health, limited access to home environments with rich language and experiences, low birth weight, limited access to high-quality preschool opportunities, less participation in many activities in the summer and after school that middle-class families take for granted, and more movement in and out of schools because of the way the housing market operates for low-income families. Differences in outcomes between high- and low-SES families may also reflect the preferences and behaviors of families and teachers. Compared to low-SES families, for example, middle- and upper-class families are better positioned to work the education system to their advantage by assuring that their children attend the best schools and get the best teachers, and they are more likely to invest in out-of-school activities that improve school outcomes such as tutoring programs, camps, and traveling. ${ }^{4}$ The preferences and behaviors of teachers are also a contributing factor in that many teachers with strong credentials tend to be reluctant to teach in schools with large concentrations of disadvantaged students than in schools with more advantaged students (Clotfelter, Ladd, \& Vigdor, 2011; Jackson, 2009).

The logical implication of the low achievement of poor children relative to their better-off counterparts is that average test scores are likely to be lower in schools, districts, or states with high proportions of poor children, all else held constant, than in those with fewer poor children. Figure 2 illustrates this negative relationship between child poverty and test scores across U.S. states in 2009, with eighth-grade reading scores in Figure $2 \mathrm{a}$ and eighth-grade math scores in Figure $2 \mathrm{~b}$. The achievement scores in these graphs are from the NAEP and are based on random samples of students in each state while state poverty rates are from the American Community Survey.

Of course, not all else is constant. Among other things that differ across states is the quality of the states' education systems. Test scores in Massachusetts, for example, far exceed their predicted levels given the state's 12 percent child poverty rate, presumably in part because the state implemented an aggressive and comprehensive education reform strategy in 1998 that included support for young children. In contrast, test scores in California, are well below those predicted for its 20 percent poverty rate, presumably in part because of its long history of limiting spending on education. Moreover, other factors may also contribute to the patterns. Massachusetts, for example, has a highly educated parental population, and California has a large immigrant population. Nonetheless, the overall negative relationship between the child poverty rate and student performance in both graphs is clear.

Consistent with the graphs, a simple bivariate regression of state test scores and state poverty rates indicates that a full 40 percent of the variation in reading scores and 46 percent of the variation in math scores is associated with variation across states in child poverty rates. The addition of one other explanatory variable related to family background, the percent of children who are members of minority groups, increases the explanatory power of the relationship to about 50 percent in reading

\footnotetext{
4 See Duncan and Murnane (2011) and the articles therein for detailed empirical analysis of many of these mechanisms.
} 

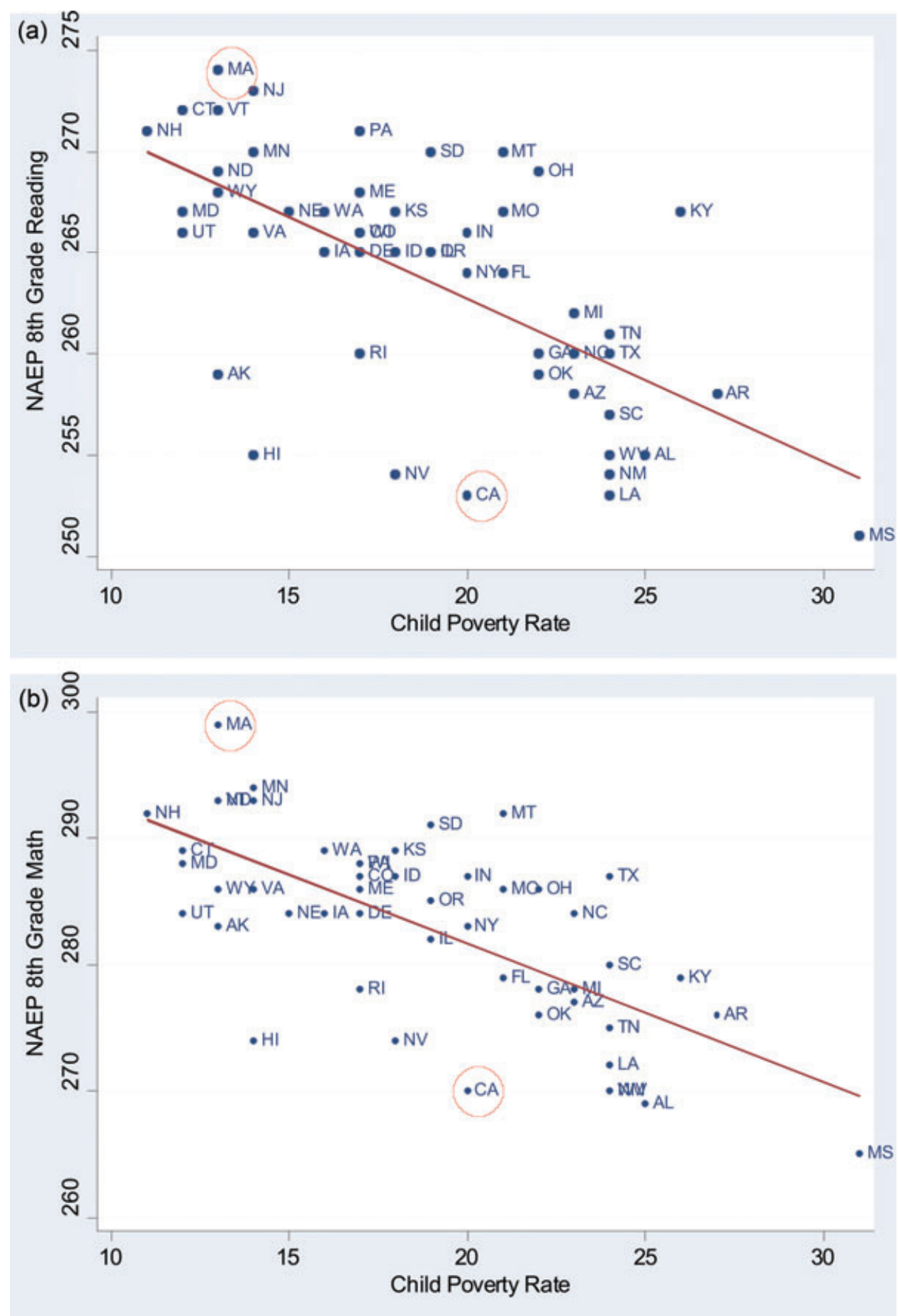

Figure 2. (a) State National Assessment of Education Progress (NAEP) EighthGrade Reading Scores and Child Poverty Rate 2009. (b) State NAEP Eighth-Grade Math Scores and Child Poverty Rate 2009. 
Table 1. Within-state changes in National Assessment of Education Progress (NAEP) test scores (standardized) as a function of within-state changes in the child poverty rate.

\begin{tabular}{lccccc}
\hline & \multicolumn{2}{c}{ 4th-Grade } & & \multicolumn{2}{c}{8 th-Grade } \\
\cline { 2 - 3 } \cline { 5 - 6 } & Reading & Math & & Reading & Math \\
\hline Child poverty rate $(\%)$ & $-0.023^{*}(0.012)$ & $-0.030^{* * * *}(0.011)$ & & $-0.030^{* * *}(0.012)$ & $-0.030^{* * * *}(0.010)$ \\
Constant & $0.402^{*}(0.209)$ & $0.514(0.194)$ & & $0.523(0.205)$ & $0.518(0.0177)$ \\
State fixed effects? & Yes & Yes & & Yes & Yes \\
Observations & 282 & 240 & & 277 & 239 \\
$R^{2}$ & 0.908 & 0.932 & & $(0.917)$ & $(0.944)$ \\
\hline
\end{tabular}

Notes: Sample is NAEP test scores (standardized across states) for years 1998, 2002, 2003, 2005, 2007, and 2009 for reading and for years 2000, 2003, 2005, 2007, and 2009 for math. Calculations are by the author.

"indicator significance at the 10 percent level, ${ }^{* * *}$ at the 5 percent level, and ${ }^{* * * *}$ at the 1 percent level.

and 51 percent in math. Clearly, the mix of family backgrounds is highly correlated with patterns of student achievement across states.

Stronger evidence that child poverty itself may be causally linked to educational outcomes, especially for math, is shown in Table 1. The estimates reported here are based on data from six administrations of the NAEP during the past 10 to 12 years and are based on panel regression models with state fixed effects. ${ }^{5}$ The outcome variables are fourth- and eighth-grade NAEP reading and math scores standardized across states. The state fixed effects control for time-invariant characteristics of a state such as its population mix and historical commitment to education that could well affect educational outcomes and that might be correlated with state poverty rates. Consistent with the view that child poverty adversely affects student achievement, the negative coefficients on the poverty rate variables demonstrate that increases in child poverty rates during the last 10 years translated into reductions in average test scores.

A strong correlation between student achievement and family background shows up as well in the international data for developed countries. The pattern emerges for comparisons both within and across countries. I focus here on test scores from the Programme for International Student Assessment (PISA) managed by the OECD (Organization for Economic Co-Operation and Development, 2010). To facilitate comparisons across developed countries of children from similar backgrounds, the OECD has constructed a measure of the economic, social, and cultural status (ESCS) of the families of all children tested. This measure incorporates information on the household's occupational status, the parents' education level, and, as a proxy for the family's income or wealth, household possessions. ${ }^{6}$ This measure is comparable to what we in the United States would call SES and is an absolute scale that allows one to compare students with similar family backgrounds across countries.

\footnotetext{
5 The years included in the analysis differ somewhat between reading and math regressions because of slight differences in when the tests were administered. The child poverty rates from 2002 to the present are from the American Community Survey and those for 2000 are from the U.S. Census. The 1998 reading scores by state are matched with state child poverty rates for 2000 .

6 The index is based on the following variables: the international socioeconomic index of occupational status of the father or mother, whichever is higher; the level of education of the father or mother, whichever is higher, converted into years of schooling; and an index of home possessions, which is based on student reports of access to education related possessions such as desks, computers and books, and availability of items such as such as televisions, cars, and cellular phones. The index is standardized to a mean of zero for the population of students in OECD countries, with each country given equal weight. A score of -1.0 on this index means that the student is more disadvantaged than five-sixths of the students in the average OECD country (OECD, 2010, p. 29).
} 


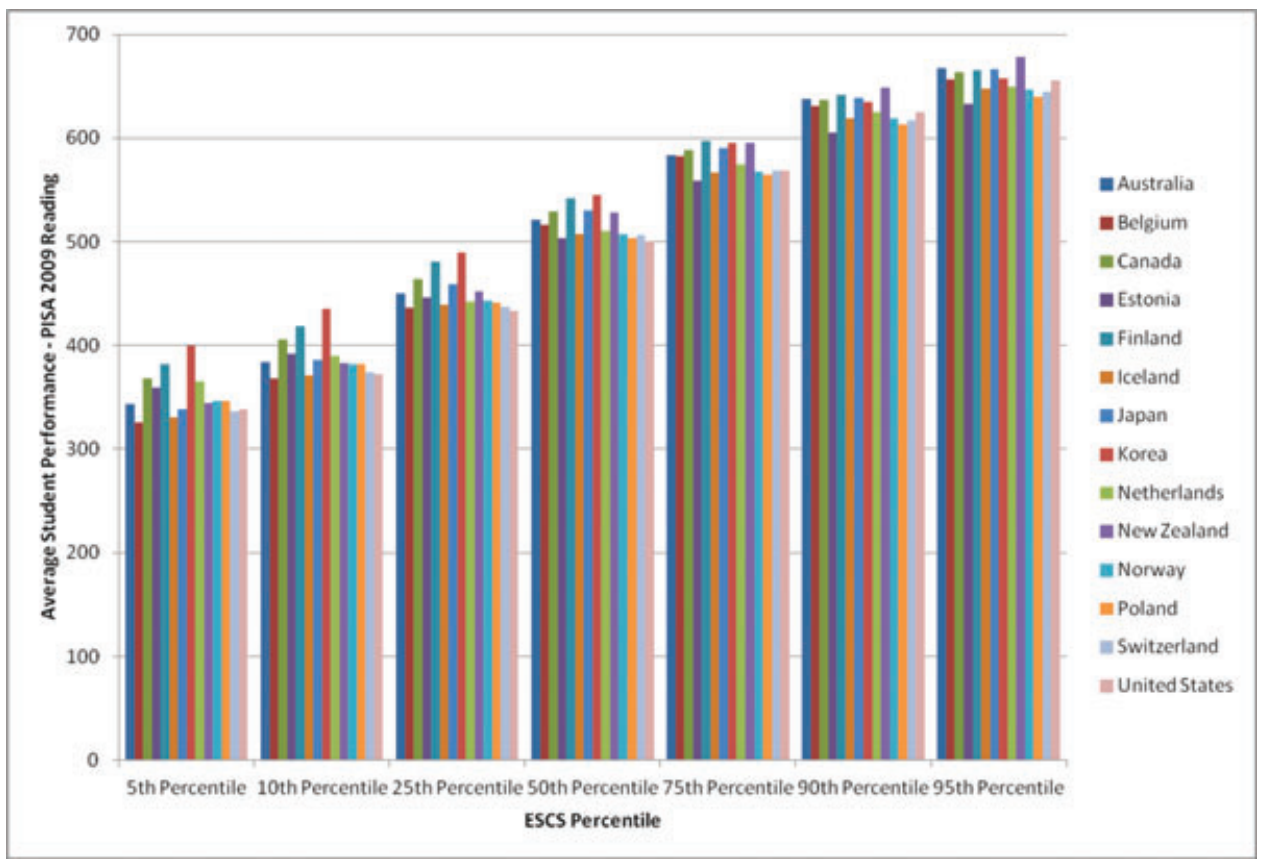

Figure 3. Programme for International Student Assessment (PISA) Reading Scores by Economic, Social, and Cultural Status (ESCS) Percentile, 14 Countries.

Figure 3 displays student performance of 15 -year olds in reading by ESCS percentile for the United States and each of the 13 countries whose students scored higher on average than U.S. students in 2009. The reported scores on the vertical axis are standardized as of 2000 to have a mean of 500 and a standard deviation of 100.

Figure 3 shows strong positive correlations between family ESCS and student performance in all 14 countries. Average test scores for students in the fifth percentile across all the countries are about 350, far below the average of about 660 for students in the 95th percentile, and the test scores rise monotonically both overall and within each country. Even in countries such as Korea, Finland, and Canada that are typically viewed as having high-performing education systems, the patterns hold: achievement levels of the low-ESCS children fall far short of those of their more advantaged counterparts.

Compared to other countries, Finland and South Korea appear to have the most success with their very low-ESCS students. This relative success largely reflects each country's strong commitment to education and to equal educational opportunity. In Finland, this commitment is rooted in the country's Lutheran heritage and the recognition that an educated population is the country's most valuable resource (Sahlberg, 2011). In South Korea, the country's historical ties to Confucianism and current efforts to expand the economy lead parents in all ESCS groups to put tremendous pressure on their children to succeed in school (Ahn, 2011). ${ }^{7}$ But

\footnotetext{
${ }^{7}$ Moreover, to keep advantaged families from gaining an advantage by putting their children in "cram" schools for additional tutoring, the government requires most high school students to remain in school until 10:00 or 11:00 each weekday night and to attend school every second Saturday. These behaviors
} 
Table 2. Programme for International Student Assessment (PISA) test scores, and child context, selected countries.

\begin{tabular}{lccccc}
\hline & $\begin{array}{c}\text { PISA } \\
\text { Reading } \\
2009\end{array}$ & $\begin{array}{c}\text { PISA } \\
\text { Math } \\
2009\end{array}$ & $\begin{array}{c}\text { Students } \\
\text { with Low } \\
\text { ESCS }(\%)^{\mathrm{a}}\end{array}$ & $\begin{array}{c}\text { Children } \\
\text { Living } \\
\text { in Poor } \\
\text { Homes }(\%)^{\mathrm{b}}\end{array}$ & $\begin{array}{c}\text { Child Well- } \\
\text { Being (UNICEF } \\
\text { Scale (1 to 6, } \\
\text { High is Better) }^{\mathrm{c}}\end{array}$ \\
\hline United States & 500 & 487 & 10.4 & 20.6 & 2 \\
Finland & 536 & 541 & 3.9 & 4.2 & 5 \\
Canada & 524 & 527 & 3.7 & 15.1 & 3 \\
Netherlands & 508 & 526 & 6.5 & 11.5 & 6 \\
\hline
\end{tabular}

Notes: ${ }^{a}$ From Organization for Economic Co-operation and Development (2010). Absolute scale across countries, approximated as percent of students more than one standard deviation below the mean.

${ }^{b}$ Percent of students with income less than 50 percent of median income within the country.

${ }^{c}$ UNICEF scale 2010. Recalculated by the author to eliminate the education component (scale $=1$ to 6 ).

even in those countries, large differences emerge between students from low- and high-ESCS families.

The performance of U.S. students (see the bars at the far right in each set) follows the same pattern as the other 13 countries. Notably, however, U.S. students in families with ESCS below the median perform particularly badly relative to their low-ESCS peers in other countries, while U.S. students from more advantaged backgrounds perform reasonably well by international standards. That is, the largest shortfalls in performance among U.S. students are concentrated among those with relatively low ESCS. These shortfalls suggest there is room for the United States to do better by its disadvantaged students.

As was true across U.S. states, these within-country patterns imply that countries with high proportions of low-ESCS students are likely to have lower overall test scores than counties in which incomes are distributed more equally. The data in Table 2 illustrate some cross-country patterns by comparing the United States to three high-performing countries: Finland, Canada, and the Netherlands. The first two columns show that U.S. 15-year olds score at lower levels on average than their counterparts in the other countries on both reading and math tests. The following three columns show that this lower average performance is not surprising in light of the significantly greater disadvantage of children in the United States relative to the other three countries.

As shown in the third column, the percentage of students living in low-ESCS families (defined by the OECD as those more than one standard deviation below the mean) in the United States, is more than 2.5 times that in Finland and Canada and 50 percent more than in the Netherlands. In contrast to the ESCS measure, which is based on an absolute scale across countries, the poverty measure in the following column is country specific and refers to the percent of students who live in households with income less than 50 percent of the country's median income. According to this measure, more than 1 in 5 children in the United States live in poverty, far more than the 1 in 25 in Finland, 1 in 7 in Canada, and 1 in 9 in the Netherlands. The final column denotes the material and health well-being of children as measured by UNICEF. The highest score of 6 for the Netherlands on this measure denotes that the country was above average among 24 countries in terms of both the material and health well-being of its children, and the lowest score of 2 for pursue nonschool activities (based on visits to Korean schools by the author in June 2011). 
the United States means that it was below-average on both measures. ${ }^{8}$ The patterns are fully consistent with the view that the low average test scores of U.S. students largely reflect our extremely high poverty rate and our relative lack of attention to the overall well-being of our children.

This pattern emerges in a more systematic manner from a large number of empirical studies based on international test score data such as Trends in Math International Mathematics and Study (TIMMS) and earlier versions of PISA, as ably summarized by Hanushek and Woessman (2010). In particular, cross-country studies estimated at both the country level and the student level find strong associations between students' socioeconomic backgrounds and their educational achievement (Hanushek \& Woessman, 2010, p. 16 and Table 6). Moreover, the studies document that these associations with educational outcomes are far stronger than those for school resources.

My reading of the patterns in Table 2, as buttressed by the evidence from the larger and more systematic empirical studies, is that it would be difficult, if not impossible, for the United States to replicate the success of higher scoring countries such as Finland, Canada, and the Netherlands by focusing on school reform alone, and that is especially true for school reform that pays little attention to meeting the social needs of disadvantaged children.

I find it useful to summarize the basic point that I am making here with the following simple functional relationship:

\section{Educational outcomes $=f($ public school quality, context $)$.}

Public school quality refers to the quality of a specific school or of a larger unit depending on whether the analysis refers to individual schools, school districts, states, or countries. Context refers here to the socioeconomic backgrounds of the students, as well as cultural considerations, including the commitment level of families to the education of their children (as I highlighted above with reference to Finland and Korea) and the success of the country in meeting the noneducation needs of children (as I highlighted with reference to the Netherlands). According to this formulation, low educational outcomes could well reflect the low quality of the public schools, or they could reflect an adverse educational context, or some combination of both. Within a single country, the SES background of the children's families is likely to be the most important component of context.

Defining and measuring what I have labeled "public school quality" raises a complex set of conceptual and empirical issues that Susanna Loeb and I have addressed elsewhere (Ladd \& Loeb, in press). Two points about the concept as I am using it in this formulation are worth noting. First, because context matters, educational outcomes alone-even far richer and more comprehensive measures than the student test scores now being used in the United States-cannot serve as an appropriate proxy for school quality. To serve that role, at a minimum they would need to be adjusted for the relevant educational context of the school, district, or state.

Second, it may be helpful to think of public school quality as the direct output of the education system, where the system includes the managerial input of state and local education policymakers, school-level inputs such as teachers and principals, and educational resources such as technology, facilities, and instructional materials. School quality may differ across schools or jurisdictions because of differences in

\footnotetext{
8 The UNICEF overall measure of child well-being also includes educational well-being. I deleted the educational well-being component for this analysis to focus on the non-education components of child well-being (UNICEF, 2010).
} 
both the quantity and quality of inputs as well as in the effectiveness with which they are used. Because of the complexity of the concept, it is difficult to measure public school quality in practice, and is probably best done through some combination of cost-adjusted resources and direct observation (Ladd \& Loeb, in press).

The functional relationship highlights that while education policymakers have direct control over school quality, they have less control over educational outcomes because of the role that context-and particularly the family background of the students-plays in shaping educational outcomes.

\section{POSSIBLE POLICY RESPONSES TO THIS EVIDENCE}

I now turn to the potential policy responses to the empirical correlation between educational outcomes and educational context. Policy responses depend in part on the policy goals. Throughout the rest of my talk, I will assume there are two interrelated goals: one is to increase average educational outcomes, and the other is to reduce skills and attainment gaps between advantaged and disadvantaged students. Raising average achievement or performance levels is often justified in terms of the need to prepare graduates for a knowledge-based society and the desire to make sure U.S. workers remain competitive with their international counterparts for future jobs. Perhaps even more important, a well-educated populace is essential for a functioning democracy and for the nurturing of a culturally rich and innovative society. Reducing achievement gaps recognizes the importance of education to the life chances of individuals and the fact that the United States as a whole has a stake in assuring that all citizens can participate fully in the economic and political life of the country. Of course policies that closed gaps by raising the achievement of disadvantaged students with no decline in the achievement of advantaged students would also raise average achievement.

\section{Reduce the Incidence of Poverty or Low SES}

One logical policy response to the correlations I have been describing would be to pursue policies to reduce the incidence of poverty or other contributors to low SES. That might be done, for example, through macro-economic policies designed to reduce unemployment, cash assistance programs for poor families, tax credits for low-wage workers, or an all-out assault "war on poverty" as pursued by Lyndon Johnson in the 1960s. This approach would appear to be a particularly desirable policy response in the present period given the current high unemployment rates and also the dramatic increase in income inequality in this country since the early 1970s. In the three decades after 1970, the coefficient of variation in family income increased by 40 percent (Campbell et al., 2008, Table 3.1). Moreover by 2010 the poverty rate had risen to 15.1 percent, its highest level since 1993, and the child poverty rate had risen to 21 percent.

Inattention to these inequalities is likely to lead to even greater achievement gaps in the future. Moreover, many considerations that extend well beyond the realm of education policy make a compelling case for the country to take strong steps to reduce income inequality. ${ }^{9}$

Nonetheless, I do not dwell on this policy response here. The main reason is that such a policy thrust is not in the cards, at least in the near term. With the budget crises at the national and state levels, and the strong political power of conservative groups, no one with significant political power is actively pushing the strategy of

\footnotetext{
9 See, for example, the arguments for why greater equality makes societies stronger in Wilkinson and Pickett (2010).
} 
reducing poverty and income inequality at this time. Nor are they likely to do so in the immediate future, unless the current protests in New York City and elsewhere succeed in putting the issue of income inequality back on the policy agenda. ${ }^{10}$

A second reason for not dwelling on this policy response, regardless of how desirable it may be, is that any serious effort to reduce poverty and to equalize incomes will take a long time, and the country cannot wait that long to address the educational needs of the current generation of children.

I note, however, that past efforts to address poverty and socioeconomic inequalities appear to have played some role in reducing achievement gaps, especially those between black children who are disproportionately represented among low-income families and white children who tend to come from more affluent families. In combination with other policies including civil rights initiatives, for example, antipoverty programs during the 1960 s appear to have contributed to some of the significant reduction in the black-white test score gaps during the 1960s and early 1970s. But, as I said before, I am not optimistic that such policies will be revived in the current political environment.

\section{Deny the Power of the Correlation and Expect Schools Alone to Offset Any Adverse Effects of the Educational Context}

An alternative policy response is for education policymakers simply to deny the correlation between education outcomes and family background or other relevant elements of the context. Policymakers can deny the correlation by setting the same high achievement and attainment expectations for all students and requiring all schools to meet the proficiency standard, regardless of the mix of students in the school. In other words, schools serving large proportions of low-SES students that failed to fully offset the adverse family contexts of their students would be labeled as failing schools. That is, in fact, what our current federal policy, NCLB, does.

The starting point under NCLB is similar achievement standards for all children. Specifically, it requires that all children meet grade-specific proficiency standards, as measured by test scores, by the school year 2013/2014, with the proviso that the proficiency standards can differ by state. Because many children, and especially those from disadvantaged backgrounds, started out well below the achievement standards, the legislation required states to set year-by-year goals for the schools that would move all students to proficiency by the deadline. Of course, even if we set-aside the role of family background, the goal of 100 percent proficiency is absurd unless the proficiency levels are set so low as to be meaningless. The reason is that it ignores the normal distribution of talent among individual students. But my focus here is on how the legislation in practice denies the power of the correlation between family background and student achievement for groups of students.

Under NCLB, each school must meet the same standard, regardless of whether it serves low- or high-SES students and must do so for all relevant subgroups within the school defined by income, minority status, and Limited English Proficient status. Interestingly, NCLB policy explicitly acknowledges that some groups of students are likely to perform at lower levels than others, which is fully consistent with the correlations I have been talking about. But NCLB acknowledges those differences only to make sure that the schools do not ignore the disadvantaged students. In fact, the policy is clearly based on the presumption that the schools themselves can and should offset any educational disadvantages those children bring to the classroom. In this sense, NCLB denies the correlation between family background and student achievement. 10 This is a reference to the Occupy Wall Street protests that were occurring in New York City and that
were spreading to other cities at the time this talk was written. 


\section{2 / Education and Poverty}

\section{Possible Rationales for Denial}

Why might policymakers have chosen to deny the correlation? I can think of at least four reasons.

One possibility is that policymakers believe that schools themselves should offset the effects of low SES. This normative view might reflect in part the historical observation that schooling has often served as the route to prosperity and social mobility. This normative view may also reflect the increasing importance of education to an individual's life chances. Data clearly show, for example, that the earnings of workers with low levels of education have been level or even falling in recent years for a combination of demographic, technological, and institutional reasons, while the earnings of those with a college degree have risen, which implies a significant increase in the returns to education (Goldin \& Katz, 2008).

This normative perspective suggests that it would be inappropriate-and even immoral-to let schools off the hook simply because they serve large concentrations of children who face greater educational challenges than other children. It does not, however, confront the difference between what might be desirable from a normative perspective and what is feasible in practice.

A second possible rationale for policymakers to deny the correlation between low SES and educational outcomes is that they simply do not want to set lower expectations for some groups of children than for others, or to engage in what President George W. Bush referred to as the "soft bigotry of low expectations"(quoted in Noe, 2004). The fear here is that if they set lower outcome goals for some schools than for other schools, it will become a self-fulfilling prophecy.

Sending a signal that some children are less able to learn than others would be inconsistent with the basic tenet of the standards-based reform movement. As articulated by O'Day and Smith in their well-known 1993 paper, the standards movement starts from the premise that, while it may take some children longer than others, all children can learn to high and ambitious standards. Of course, for that learning to occur, the conditions must be right. In the effort to translate their views into policy, supporters of standards-based reform paid attention to part of the required conditions by calling for "opportunity to learn" (OTL) standards (Ravitch, 1995). These OTL standards were intended to make sure that all children would have access to the quality teaching necessary for them to learn, but still implicitly assumed that schools alone could address the challenges of low-SES children. In any case, the high resource costs of implementing OTL standards made them a political nonstarter. ${ }^{11}$

Though understandable and also commendable in some ways, this reluctance even to suggest that some children face educational challenges that schools alone may not be able to address signifies a denial of the basic correlations between family background and student achievement. Simply wanting something to be true does not make it so.

A third possible rationale for denying the correlation is the evidence that some schools appear to have successfully achieved high academic results for large concentrations of children from disadvantaged family contexts. The argument is that if some schools can "beat the odds," it is reasonable to expect all schools to do so. Included among the "successful" schools are various charter schools, including the highly touted Knowledge is Power Program (KIPP) schools, as well as specific schools operated by charismatic leaders.

One must be careful about this argument for a number of reasons. One is that a close look at the data shows that many of the schools cited as being successful in

11 Discussion with Diane Ravitch, October 4, 2011. 
fact met the success criterion only in a few grades or in a single year (Rothstein, 2004 , ch. 2). Another is to the extent that the success of some of the schools is attributable to their success in attracting low-SES students from the high end of the ability or motivation distribution, it cannot be scaled up to the larger system. Yet some schools, such as many charter schools in Boston and (possibly many) of the KIPP schools, undoubtedly have successfully found a way to educate low-SES children to high levels (Angrist, Pathak, \& Walters, 2011; Tuttle et al., 2010). At best, however, such success can be generalized only to children with the types of motivated parents that apply to such schools. Also the charter schools that have beaten the odds, and especially the KIPP schools, typically have significant extra funding from philanthropic sources that permit them to do things that have not generally been viewed as feasible within the traditional public schools, such as offering longer school days, Saturday classes, and longer school year and requiring teachers to teach longer hours.

That some individual schools have raised achievement levels for children from disadvantaged families is undoubtedly a good thing, at least for the children who attend such schools. At the same time, believing that one can simply extrapolate from these few success stories to the system as a whole requires a willful denial of the basic empirical relationship between SES and educational achievement.

A fourth potential rationale for denying the correlation is more nefarious. This rationale is the desire to discredit schools and generate pressure for greater privatization of the education system. The requirement under NCLB that all schools meet the same high standards for all their students inevitably will lead either to large numbers of failing schools or to dramatic lowering of state standards. Both outcomes serve to discredit the public education system and lend support to arguments that the system itself is failing and needs to be changed in major ways. The importance of this rationale for denying the correlation and supporting NCLB in its current form is hard to gauge, but my guess it that it played some role, at least among some policymakers. ${ }^{12}$

\section{Evaluation of NCLB}

Regardless of the potentially laudable intentions of some of NCLB's advocates, their rationales for denying the contribution of family background to educational outcomes are flawed. Because NCLS is built on this sort of denial, it a deeply flawed policy. The evidence on NCLB, briefly summarized here, supports this assertion.

The evidence suggests that NCLB has not succeeded in raising student test scores, as measured by the nation's report card, the NAEP, by anywhere near the desired amounts (Dee \& Jacobs, 2011). At best, it has raised the average math scores of fourth graders by a small amount, with somewhat larger effects for disadvantaged students at that level. The effects on eighth-grade math scores may be positive but are not clear, and no effects emerge for reading scores at either the fourth- or eighth-grade levels.

At the same time NCLB has generated a range of undesirable side effectsincluding large numbers of failing schools, ${ }^{13}$ narrowing of the curriculum, low

\footnotetext{
12 Consistent with this perspective in a slightly different context is the response of Chester Finn (a former chair and member of the National Assessment Governing Board) to concerns about the high proficiency cut scores proposed for the National Assessment of Educational Progress. The realism of the cut scores was less important, he argued, than of demonstrating that many students were failing in order to send a signal to the nation about the urgency of improving education (reported in Rothstein, Jacobsen, \& Wilder, 2008, p. 62.)

13 Tracking reports show 38 percent of schools nationwide and more than half of the schools in 12 states and District of Columbia are currently not meeting the annual requirements of the NCLB legislation. The
} 


\section{4 / Education and Poverty}

morale among teachers who are facing pressure to achieve goals that they cannot meet, and, as has become abundantly clear in recent months by the cheating scandals in Atlanta and elsewhere, significant amounts of cheating by teachers under extreme pressure to raise student test scores.

In recognition of these failures of NCLB, an increasing number of policymakers are acknowledging that it would be desirable to shift away from the absolute standard to some form of value-added measure of school effectiveness. I have more to say about that approach in the next section.

\section{Set the Context Aside and Focus on Improving School Quality by Reducing Inefficiencies}

An alternative policy response to the correlation between context and educational outcomes is for education policymakers to set contextual considerations aside on the ground that they can do little to change them. Thus, while policymakers might well be aware of the importance of family background and other relevant aspects of the context, they choose to ignore that aspect of the educational challenge and to focus their attention exclusively on making schools themselves work better, something over which they have direct control. Although this approach is preferable to the approach of outright denial, it is likely neither to raise overall achievement, nor to reduce achievement gaps very much, and could do serious harm.

In practice-but not by necessity because school quality could also be improved by investing more resources in education-this policy response in recent years has started from the perception that the U.S. education system is rife with inefficiencies and that the inefficiencies can be eliminated by better use of information and incentives. The intent is to get better outcomes with few or no new resources. This strategy could potentially also reduce achievement gaps if the policy reduced inefficiencies more in the high-poverty schools relative to the low-poverty schools.

NCLB, itself, has been justified in part by this logic. Lack of adequate parental monitoring of schools, argue some, means that external monitoring and incentives are needed to induce schools to work harder to meet governmental goals. By measuring, reporting and, in many cases, attaching positive consequences to strong performance and negative consequences to weak school performance, policymakers provide incentives for schools and school districts to focus attention of what is being measured and to work either harder or "smarter."

Two other strategies currently on the policy agenda fit into this policy response category of reducing inefficiencies. One is the use of student test scores for evaluating teachers for high stakes purposes and the other is governance changes in the form of charter schools and vouchers to promote competition and innovation.

\section{Test-Based Evaluation of Teachers}

Research suggests that individual teachers are the most important school-related factor affecting student achievement and that there is wide variation in quality among teachers, both across and within schools. ${ }^{14}$ Moreover, the data show that it

percentage of failing schools differs across states with the toughness of the state's proficiency standards. Moreover, with no change in the law or without the new waiver policy recently enacted by the Obama administration, the percentages of failing schools are likely to increase significantly in the next few states because many states backloaded the increases required to meet the 2014 goals (Center on Education Policy, 2011).

${ }^{14}$ In fact, while the evidence suggests that teachers may be more important than small class sizes, it is worth noting that no studies compare the impact of teachers to a variety of other inputs such as principal quality or the coherence of the curriculum. (See Rothstein, 2004, http://www.epi.org/publication/ib286/.) 
is extremely hard to fire teachers. Based on this research, many policymakers are convinced that the use of student test scores for the purposes of evaluating teachers will improve school quality by reducing the disparities in teacher quality within and across schools. ${ }^{15}$

The good news here is that policymakers are increasingly accepting the idea that when using student test scores for the purposes of evaluating teachers, it makes more sense to use some form of value-added measure rather than the raw test scores. Because value-added measures take into account the achievement levels that children bring to the classroom, the measures isolate, at least in principle, the contributions of specific teachers to student learning. In this sense, policymakers are explicitly recognizing that some students start the year less well prepared than others, and they are acknowledging that individual teachers should not be held responsible for achievement differences that are outside their control.

By attaching stakes to these value-added measures, education policymakers hope to incent existing teachers to work harder toward the goal of raising student achievement, to provide objective information to school leaders designed to make it easier for them to remove ineffective teachers, and to attract a new brand of teachers to the profession, teachers who are less interested in job security and more interested in being rewarded for good performance.

The attention to value-added, however, does nothing by itself to help teachers address the educational challenges that disadvantaged children bring to the classroom. In that sense, it ignores the correlation between family background and student performance. Even if it were true that value-added models generated valid and reliable measures of teacher effectiveness (which extensive research shows they generally do not), this focus on teacher effectiveness at best pushes teachers to work hard toward the goal of raising student test scores, with no attention paid to other academic and nonacademic needs of children that may impede their ability to learn (Baker et al., 2010). As a consequence, while this policy focus could potentially improve some educational outcomes, it will do so only if the policy diagnosis of rampant inefficiency is correct. To the extent that policymakers are misreading the situation and attributing educational shortfalls-especially those in high-poverty schools-to production inefficiencies rather than to context, the strategy is not likely to be very effective, and could do some serious harm. How much good it does in practice is an empirical question.

The best U.S. evidence to date indicates that providing financial incentives for teachers to raise test scores does not lead to the desired results. In a recent experiment in which randomly assigned math teachers in grades 5 to 8 in Nashville were offered large bonuses for raising their students' test scores, for example, no differences emerged in the test scores of those teachers offered the incentive and those in the control group (Springer et al., 2010). ${ }^{16}$ More generally, the focus on test-based evaluation of teachers provides incentives for them to narrow the curriculum to the tested subjects of math and reading and to direct teacher attention to basic skills away from student reasoning skills. In addition, statistical problems of bias and unreliability can lead to unfair and arbitrary treatment of teachers, which in turn lowers morale and reduces the appeal of teaching as a profession (Baker et al., 2010).

I am not suggesting that existing methods for evaluating and developing teachers are adequate. Instead, my point is that evaluations that place heavy weight on

15 At least one prominent education researcher has argued that replacing the 5 to 10 percent of the weakest teachers would generate outcomes for U.S. students that are similar to those in Finland or Canada (Hanushek, 2010).

16 Other rigorous studies with more positive results are based on experiments in other countries and, for a variety of reasons, may not be directly relevant to the United States. For a full discussion, see Hout and Elliotts (2011). 
student test scores are likely to do more harm than good because they start from the assumption that teachers are shirking rather than the assumption that they need support and constructive counseling. Peer assistance and review programs that combine support with accountability appear to be a more promising alternative to the current system. ${ }^{17}$

\section{Governance Changes Designed to Promote Efficiency}

Also high on the school reform agenda of those seeking more efficient schools are governance changes in the form of charter schools and voucher programs. Charter schools are publically funded schools operated by nonprofit or private companies that have significantly more autonomy than the traditional public schools. Voucher programs provide financial support for families to send their children to private schools. I focus here on charter schools because of their greater prevalence relative to voucher-funded private schools and because the Obama administration has been actively pushing states to expand charter schools.

To the extent that charter schools are intended to provide new-and betterschooling options for disadvantaged children, they would appear to be addressing the educational challenges of disadvantaged students. And indeed some charter schools are doing that. As I mentioned earlier, a few charter schools appear to be doing a good job of promoting academic success among children from disadvantaged families, albeit often with the help of substantial additional resources from private philanthropists or from charismatic leaders.

Despite these highly touted successes, charter school reform effort as a whole is more appropriately viewed as a governance change that ignores the educational challenges facing disadvantaged children than a reform that targets those challenges directly. I say that for several reasons. One is that many states are increasingly justifying the expansion of charter schools on the ground that they will provide necessary competition to the traditional public sector, which is viewed by many reformers as bureaucratic and excessively beholden to unions. The competitive pressure from charter schools, it is hoped, will force traditional schools to use their resources more efficiently. Thus, a major justification for charter schools is similar to that for the test-based evaluation of teachers, namely that inefficiency is a significant cause of the poor average performance of U.S. students relative to other countries.

In addition, there is little reason to believe that governance changes alone will lead schools to address in a systematic way the challenges facing disadvantaged students. In the absence of significant additional external financial and programmatic support, charter schools serving disadvantaged students are likely to be no more successful in raising achievement levels than their traditional public school counterparts and indeed may be less so given the challenges in running a school and the large concentrations of disadvantaged students found in some charter schools. Consistent with this prediction, the evidence suggests that on average charter schools are either less effective or no more successful than traditional public schools, although some studies suggest that they may generate some positive achievement gains for low-income students (Raymond, 2009; Gleason et al., 2010). The patterns were particularly dramatic in my 2007 study of charter schools in North Carolina with Robert Bifulco, where we found that the students in charter schools serving large proportions of minority students exhibited even greater adverse effects on

17 See, for example, the reports produced by The Project on the Next Generation of Teachers at the Harvard Graduate School of Education (http://htttp://gse.harvard.edu/ ngt/). Also see study by Tyler et al. (2011). 
student achievement than students in charter schools serving more middle-class students (Bifulco \& Ladd, 2007). Thus, there is little evidence that charter schools in practice are providing better schooling options on average for disadvantaged children. Indeed the movement could be harming the options for some children by draining funds from the traditional public schools that continue to serve the bulk of disadvantaged students.

This discussion should not be interpreted as an argument either for or against charter schools. My own personal view is they have a role to play in any overall education system, but that role should be limited to the fringe of the system (Fiske \& Ladd, 2001). The main point is that governance changes of this type do little in a systematic way to improve outcomes for disadvantaged children. At the same time, policymakers can learn from the success stories. One central lesson from the KIPP schools, for example, seems to be that some disadvantaged children thrive on longer school days, a clear focus on goals, a no-excuses culture, and more parental involvement (Angrist, Pathak, \& Walters, 2011).

\section{Directly Address the Educational Challenges Faced by Low-SES Children}

A fourth policy response to the correlation between family background and student outcomes is for education policymakers to work with other agencies and community groups to pursue strategies specifically designed to reduce the adverse impact of low SES on educational outcomes-both for the low-SES children themselves and for other children. Such an approach, in my view, must be an essential component of any serious effort to reduce achievement gaps and to raise student achievement. Instead of denying or ignoring the context, this approach specifically acknowledges and confronts the evidence in a serious manner by addressing the symptoms or correlates of poverty that directly impede student learning.

Here is where policy researchers, and especially APPAM researchers, have a large role to play. Many of you have done, and are currently doing, excellent research along these lines. I particularly commend the research in the new Russell Sage volume edited by Greg Duncan and Richard Murnane, entitled Whither Opportunity? Rising Inequality and the Uncertain Life Chances of Low-Income Children. The papers in this book document the many mechanisms through which rising income inequality in this country widens the educational gap between low-income and higher income children.

But there is much more work to be done, particularly by teams of interdisciplinary researchers who pay close attention to local context, address topics that do not fit neatly into clearly defined policy silos, and address the very real political and organizational constraints that typically limit the purview of educational decisionmaking. I outline here two central components of this policy approach, addressing the education-related challenges facing low-SES children and assuring that all children have access to high-quality schooling.

\section{Addressing the Education-Related Challenges of Low-SES Children}

The observation that low SES is highly predictive of poor educational outcomes by itself provides little guidance for education policymakers who have little or no control over the backgrounds of the students, at least in the aggregate, within a community. To address those challenges, policymakers need to understand the mechanisms through which low SES translates into educational gaps.

Fortunately, we already know a lot about those mechanisms. Research reviewed by Janet Currie, for example, documents a clear link between child poverty and poor health outcomes and how many of those poor health outcomes translate into 
low cognitive outcomes (Currie, 2009). Other researchers have documented how an impoverished early childhood limits access to language and problem-solving skills and to variation in experiences that serve as the basic springboard for future learning. In addition, family poverty and low SES during the school years translates into limited access to books and computers at home or to activities away from home in "novel" places (Phillips, 2011). Family poverty during the school years is also typically associated with significant residential movement as families struggle to find stable housing arrangements. Such movement is disruptive not only for the children who move in and out of schools, but also for the other children in schools with high proportions of mobile students (Raudenbush, Jean, \& Art, 2011). Children in low-income families also experience far more learning loss during the summer than do their peers from more affluent families.

The policy implications of these patterns are straightforward at one level, but difficult to implement effectively in practice. Those difficulties reflect the absence of simple solutions that apply to all situations, the high costs of some quality programs, the need for government agencies and community groups to work together, and the difficulties of taking programs to scale. I provide examples of three types of policy interventions here.

Early Childhood and Preschool Programs: Already on the national and state policy agendas are efforts to compensate for impoverished early childhood experiences with early childhood and preschool programs. Rigorous evaluations of a few intensive, high-quality programs, such as the Carolina Abecedarian and the High Hope/Perry Preschool Project, demonstrate strong positive effects on program participants that persist into adulthood (Mervis, 2011), but the path from small randomized controlled trials to public policy is not straightforward (Gormley, 2011). Although many positive outcomes also emerge from evaluations of the federal Head Start and Early Head Start programs and various state programs, the results from studies of these larger and less intense programs are somewhat mixed (Barnett, 2011).

Moreover, missing from most of the existing studies is attention to the broader effects of programs when implemented at scale and evaluation of effects on all groups of children in a community, not just the participants. My own recent work with my Duke colleagues, Kenneth Dodge and Clara Muschkin, which relies on data from all births in North Carolina for multiple birth cohorts linked to third-grade test scores begins to fill that gap. We (Ladd, Muschhin, \& Dodge, 2011) examine the community-wide effects of two highly touted North Carolina programs, one focused on the early years of childhood, and the other on four-year olds and find that both programs generate moderately large positive effects on third-grade outcomes for both programs. But our work is still in an early stage and applies to only one state. Moreover, it represents only one small part of a much larger research agenda, one that must also include attention to the best ways to assure quality services. Of major concern, going forward is that the severity of state budget crises may undercut the programmatic gains that have been made in recent years.

School-Based Health Clinics and Social Services: Many other countries are far ahead of the United States in addressing the health and developmental needs of their children. In Finland, for example, all children are required to have health examinations at ages 2 and 5. These examinations assess the child's developmental level as well as physical health, and the records follow the children into school. In this way, schools and parents can address the developmental needs of children early. School welfare teams composed of school nurses, social welfare counselors, and teachers meet on a regular basis to discuss and address the challenges of individual children. The 
Finns take pride in the fact that they identify close to a third of their children in the early years of schooling as needing special services, and that the proportion needing special attention declines as children progress through school. ${ }^{18}$

The situation differs in the United States. Assuring that all children have access to health insurance has been on the policy agenda in recent years, but access to insurance alone does little to assure that children obtain the health care they need to thrive in school. A more direct approach, now being implemented in some places, is to set up health clinics in the schools serving large proportions of disadvantaged students or at a minimum to assure that all children have easy access to clinics. These health clinics can provide routine and preventative care, provide services to children with acute health problems in a timely manner, monitor children's health in a systematic way as they progress through school, and can address basic dental and vision problems that might otherwise impede children's learning. Strict confidentiality requirements related to medical records makes it difficult to examine the effects of such clinics on individual participants, but it would be useful for researchers and practitioners to work together to experiment with and to evaluate efforts of this type (see Geierstanger et al., 2004 for a summary of existing research and its limitations).

Children's learning can be impeded not only by poor physical health. It can also be impeded by poor mental health and depression caused by problems at home, including domestic abuse, divorce, alcoholism, depressed parents, and work-related stress, problems that require attention from social service agencies. In some cases, children get the help they need through existing agencies. But many others may suffer in silence in ways that keep them from functioning effectively in the classroom. A logical policy response is to provide mental health and social welfare counselors in schools, especially in schools with large concentrations of disadvantaged children who are least likely to have access to the resources they need to deal with their challenges. A 2000 comprehensive review of the literature on school-based mental health services concluded that many provided positive benefits but that most evaluations ignored or underemphasized school-relevant outcomes (Rones \& Hoagwood, 2000).

I applaud the recent efforts of researchers to measure the effects of mental health counselors in elementary schools, and I would strongly support more research of this type. In a recent study, for example, Randall Reback (2010) used cross-state differences in state policies to document that elementary school students in states with more aggressive school counselor policies were associated with greater test scores gains and that the polices were causally linked to teachers' perceptions of school climate. In addition, Carrell and Hoekstra (2010) find large effects on student test scores from the presence of counselors in elementary schools, with the effects identified by within school variation over time in access to services. Much as it distresses me to acknowledge the current cutbacks in school nurses and counselors associated with budget pressures in many states, I note that such cutbacks could provide opportunities for researchers to examine the effects of removing the supports.

After-School and Summer Programs: American children typically spend very little time in school. On a typical school day, most children spend less than half their nonsleeping hours in school and over the course of the year they spend fewer than

18 Presentation by Finnish National Board of Education to a North Carolina Delegation of Educators, September 26, 2011. 
half of all days in school. This short time in school puts low-SES children at a significant learning disadvantage relative to their more advantaged peers whose parents are often able to provide them a rich set of opportunities for learning outside of school, whether that be after school, on weekends, or during the summer. The rising gap in incomes has been accompanied by a rising gap in the amount highand low-income families spend on out-of-school enrichment activities such as music lessons, travel, and summer camps. ${ }^{19}$ These activities matter not only because they are enriching in their own right, but also because they provide experiential background useful for learning as children progress through school.

Many other countries have been far more aggressive than the United States in equalizing these opportunities through extended school hours, after-school and summer programs, and extended year programs. Many Dutch schools have been converted into community schools, for example, with a variety of enrichment activities after school hours. The Koreans go to the (undesirable, in my view) extreme of keeping all high-school students in school late into the evening specifically to keep middle-class families from taking advantage of evening hours to put their children in extra tutoring programs. Within the United States, some charter schools, and particularly the KIPP schools, have pursued the strategy of a longer school day, week, and year, and many nonprofit groups are now supporting after-school programs.

The evidence on the effectiveness of after-school programs and summer schools is somewhat mixed (Cooper et al., 2000). As is true for many of the programs mentioned here, the quality and nature of the program matter. Research shows, for example, that marginally expanding in-school time without improving how that time is used does not improve learning. At the same time, some high-intensity summer programs have generated academic gains in high-poverty areas, and some low-cost reading programs have reduced summer reading loss (Allington et al., 2010; Jacob \& Lefgren, 2004, Kim \& White, 2011). Clearly, much more experimentation and research would be useful.

\section{Providing High-Quality Schools for Disadvantaged Students}

It does little or no good for policymakers to address the out-of school challenges of disadvantaged children, however, if the schools those children attend are low quality. Researchers have shown, for example, that one reason for the more rapid fading of Head Start benefits for black than for white participants in that the black children ended up in lower quality elementary schools than their white counterparts (see overview in Currie, 2001). Thus, a central component of any policy agenda designed to address the needs of children from disadvantaged families is to assure that the schools such children attend are high quality.

To achieve that end, policymakers must assure, first, that children in schools serving large proportions of disadvantaged students have access to high-quality teachers, principals, supports for students, and other resources and, second, that the schools are held accountable for the quality of their internal processes and practices. At the risk of being criticized by some groups within the education policy community for daring to suggest that it is time for education policymakers to end their obsession with test-based outcome measures of school quality and to shift the focus to the quality of inputs and school processes, that is exactly what I am proposing here.

19 The spending gap between families in the top and bottom family income quintiles was approximately $\$ 2,700$ in the early 1970 s (in 2008 dollars) and rose to $\$ 7,500$ by 2005 to 2006 (Kaushal, Magnuson, \& Waldfogel, 2011). 
Assuring Quality Inputs: Research studies consistently document that high-poverty schools typically have teachers with lower qualifications along many dimensions than schools with more advantaged students. My own work with Duke colleagues clearly demonstrate that pattern for North Carolina schools, with particularly large discrepancies in teacher credentials across high- and low-poverty middle schools, with the same patterns emerging for school principals (Clotfelter et al., 2007). Further, ambitious work by Heather Hill and colleagues show that math teachers in high-poverty schools have lower math knowledge for teaching (based on a measure that is distinct from math content knowledge or degrees) than their counterparts in more advantaged schools (Hill, 2007).

The policy challenge is to find ways to even out the distribution of teacher and principal quality across schools. Although it may be tempting to attribute the current maldistribution largely to the provisions of union contracts, that is a mistake. One need only observe that patterns emerge not only in unionized states, but also in nonunion states such as North Carolina. Research shows that teacher preferences play a fundamental role in the uneven distribution; although not all teachers are reluctant to teach in high-poverty or high minority schools, many apparently are (Clotfelter, Ladd, \& Vigdor, 2011; Jackson, 2009). Hence, the challenge is to find ways to make schools serving disadvantaged children more attractive to high-quality teachers than they currently are. Education policymakers can do so by implementing school assignment policies designed to balance the socioeconomic or racial mix of students across schools; making sure that high-poverty schools have strong school leadership and the support services such as nurses and social workers required for teachers to be successfully with their students; and by using financial incentives to attract and retain teachers in schools with large proportions of challenging-toeducate children. Because states and districts are responsible for the quality of these inputs, they are the ones, not the schools themselves, who should be held accountable for any shortfalls.

Holding Schools Accountable: At the same time, individual schools also should be held accountable, but only for things that are under their control. Specifically, they should be held accountable for the internal policies and practices that help to produce a far broader set of educational outcomes than student achievement alone as measured by test scores. Schools might be held accountable, for example, for providing a safe and supportive school environment and a climate that promotes respect among children and teachers; for tracking the individual developmental needs of all the children they serve and for implementing strategies to address those needs; and for delivering the curriculum in a coherent manner that engages students as partners in the learning process and appropriately pushes them all to the limits of their abilities.

Clearly, accountability of this type is a far cry from the punitive test-based accountability that we now have in this country. One starting point for this new form of accountability would be the school inspectorates that are common in many countries around the world. My own research on education review offices or inspectorates in New Zealand and the Netherlands suggests that there is no one perfect model, or even a single best model that could or should be directly transferred to the United States (Ladd, 2010). Nonetheless, I believe that it is time for the United States to start experimenting with an inspectorate approach that involves human judgment and, if well implemented, has the potential to provide useful and constructive guidance to individual schools on how they can become more effective (Ladd, 2007).

Even in a more positive and constructive accountability system along these lines, student tests would continue to play a role. An expanded version of the NAEP that covered more subjects would permit states to determine the areas in which they 
are doing well or poorly relative to national norms (Rothstein, Jacobsen, \& Wilder, 2008). And at the school level, teachers would continue to give tests and other assessments for the purposes of diagnosing the strengths and weaknesses of their students. One of the things schools would be held accountable for would be their procedures for measuring student learning, and for their systems for responding to those results, including making sure the children get the social services they need to succeed. The point is that school quality would be defined in terms of how well schools are operated with the goal of meeting the educational needs of all their children. ${ }^{20}$

Such a shift would move us away from a failed and punitive test-based accountability system that does not work in favor of an approach that has the potential to be far more constructive and also more consistent with the broad set of aspirations we have for our public education system.

\section{CONCLUSION}

Such bolder and broader strategies designed to address the educational needs of low-income children will cost money, could be complex, and undoubtedly will need to differ from place to place depending on the local context. Because many of the policies must be tailored to the local context, state and local communities will have to play a major role.

The most productive step for the federal government in the short run would be to eliminate NCLB. The logic of my argument this afternoon is that in its place, the federal government should implement strategies designed to help state and local governments address in a more constructive and positive manner the educational needs of low-SES children and to assure that poor children have equal access to quality schools. Ideally, the longer-run agenda should also include a major effort to reduce child poverty.

More research is needed both on the mechanisms such as poor physical and health, limited out-of-school opportunities, and family stress through which poverty adversely affects student learning, and on the programs and combinations of strategies best suited to address these challenges. Because these strategies are likely to require action by multiple governmental agencies and to cut across a number of policy areas, I invite those of you who work in the interrelated areas of education and social policy to engage with others who focus on organizations and management in this important endeavor to reduce the impact of poverty and low SES on educational outcomes.

HELEN F. LADD is the Edgar, Thompson Professor of Public Policy at the Sanford School of Public Policy, Duke University, Durham, NC 27708.

\section{ACKNOWLEDGMENTS}

This is the written version of my Presidential Address to the Association for Public Policy Analysis and Management in Washington, D.C., November 4, 2011. I thank my husband, Edward Fiske; the faculty and student participants in the Sanford School Seminar Series; and Richard Rothstein for their helpful comments and criticisms on earlier versions of this paper. In addition, I am grateful for the research assistance of Duke students, Sarah Fuller, Laura Nickelhoff, and Pavithra Mahesh, and to Dania Frank for sharing her file of NAEP data and to Sean Reardon for providing the data for Figure 1. Although the ideas in this

\footnotetext{
20 A model accountability system along these lines has been proposed by the Campaign for a Broader, Bolder Approach to Education (Boldeapproach.org).
} 
paper are my own, they reflect the insights I have developed during the past several years from my close involvement with the Campaign for a Broader, Bolder Approach to Education (Boldapproach.org).

\section{REFERENCES}

Allington, R. L., McGill-Franzen, A., Camilli, G., Williams, L., Graff, J., Zeig, J., Zmach, C., \& Nowak, R. (2010). Addressing summer reading setback among economically disadvantaged elementary students. Reading Psychology, 31, 411-427.

Ahn, B. M. (2011). Education in South Korea: National treasure or national headache? Paper presented at the annual conference of the Association for Education Finance and Policy, Seattle, WA.

Angrist, J. D., Pathak, P. A., \& Walters, C. R. (2011). Explaining charter school effectiveness. National Bureau for Economic Research, Working Paper No. 17332. Cambridge, MA: National Bureau for Economic Research.

Baker, E. L, Barton, P. E., Darling-Hammond, L., Haertel, E., Ladd, H. F., Linn, R. L., Ravitch, D., Rothstein, R., Shavelson, R. J., \& Shepard, L. A. (2010). Problems with the use of student test scores to evaluate teachers. Economic Policy Institute Briefing Paper \#278. Washington, DC: Economic Policy Institute. Retrieved October 25, 2011, from http://www. epi.org/page/-/pdf/bp278.pdf.

Barnett, W. S. (2011). Effectiveness of early educational intervention. Science, 333, 975-978.

Berliner, D. C., \& Biddle, B. J. (1995). The manufactured crisis: Myths, fraud, and the attack on America's public schools. Cambridge, MA: Perseus Books Group.

Bifulco, R., \& Ladd, H. F. (2007). School choice, racial segregation and test score gaps: Evidence from North Carolina's charter school program. Journal of Policy Analysis and Management, 26, 31-56.

Campbell, M. E., Haveman, R., Wildhagen, T., \& Wolfe, B. L. (2008). Income inequality and racial gaps in test scores. In K. Magnuson \& J. Waldfogel (Eds.), Steady gains and stalled progress: Inequality and the black-white test score gap (pp. 110-136). New York: Russell Sage Foundation.

Carrell, S. E., \& Hoekstra, M. (2010). Are school counselors a cost-effective education input? Working Paper. Davis, CA: University of California, Davis, Department of Economics. Retrieved October 25, 2011, from http://www.econ.ucdavis.edu/ faculty/scarrell/counselors_input.pdf.

Center on Education Policy. (2011). Update with 2009-10 data and five-year trend. How many schools have not made adequate yearly progress? Washington, DC: Author.

Clotfelter, C. T., Ladd, H. F., Vigdor, J. L., \& Wheeler, J. (2007). High poverty schools and the distribution of teachers and principals. North Carolina Law Review, 85, 1345-1380.

Clotfelter, C. T., Ladd, H. F., \& Vigdor, J. L. (2011). Teacher mobility, school segregation, and pay-based policies to level the playing field. Education Finance and Policy, 6, 399-438.

Cooper, H., Charlton, K., Valentine, J. C., Muhlenbruck, L., \& Borman, G. D. (2000). Making the most of summer school: A meta-analytic and narrative review. Monographs of the Society for Research in Child Development, 65, 1-127.

Currie, J. (2001). Early childhood education programs. Journal of Economic Perspectives, $15,213-230$.

Currie, J. (2009). Healthy, wealthy, and wise: Socioeconomic status, poor health in childhood, and human capital development. Journal of Economic Literature, 47, 87-122.

Dee, T., \& Jacobs, B. (2011). The impact of No Child Left Behind on student achievement. Journal of Policy Analysis and Management, 30, 418-446.

Duncan, G., \& Murnane, R. (2011). Whither opportunity? Rising inequality and the uncertain life chances of low-income children. New York: Russell Sage.

Fiske, E., \& Ladd, H. F. (2001). Lessons from New Zealand. In P. E. Peterson \& D. E. Campbell (Eds.), Charters, vouchers, and public education (pp. 59-79). Washington, DC: Brookings Institution Press. 
Geierstanger, S. P., Amaral, G., Mansour, M., \& Walters, S. R. (2004). School-based health centers and academic performance: Research challenges and recommendations. Journal of School Health, 74, 347-352.

Gleason, P., Clark, M., Tuttle, C. C, \& Dwoyer, E. (2010). The evaluation of charter school impacts: Final Report. NCEE 2010-4030. Washington, DC: National Center for Education Evaluation and Regional Assistance, Institute of Education Sciences, U.S. Department of Education.

Goldin, C. D., \& Katz, L. F. (2008). The race between education and technology. Cambridge, MA: Harvard University Press.

Gormley, W. T., Jr. (2011). From science to policy in early childhood education. Science, 333, 978-981.

Hanushek, E. (2010). The economic value of higher teacher quality. Paper no. 16606. Cambridge, MA: National Bureau of Economic Research.

Hanushek, E. A., \& Woessman, L. (2010). The economics of international differences in educational achievement. NBER Working Paper 15949. Cambridge, MA: National Bureau of Economic Research. Retrieved October 25, 2011, from http://www.Nber.org/papers/w15949.

Hill, H. C. (2007). Mathematical knowledge of middle school teachers: Implications for the No Child Left Behind policy initiative. Educational Evaluation and Policy Analysis, 29, 95-114.

Hout, M., \& Elliotts, S. W. (Eds.). (2011). Incentives and test-based accountability in education. Committee on incentives and test-based accountability in public education. Washington, DC: The National Academies Press.

Jackson, C. K. (2009). Student demographics, teacher sorting, and teacher quality: Evidence from the end of school desegregation. The Journal of Labor Economics, 27, 213256.

Jacob, B. A., \& Lefgren, L. (2004). Remedial education and student achievement: A regressiondiscontinuity analysis. The Review of Economics and Statistics, 86, 226-244.

Kaushal, N., Mangnuson, K., \& Waldfogel, J. (2011). How is family income related to investments in children's learning ? In G. Duncan \& R. Murnane (Eds.), Whither opportunity? Rising income inequality and the uncertain life chances of low-income children (pp. 187207). New York: Russell Sage Foundation.

Kim, J. S., \& White, T. G. (2011). Solving the problem of summer reading loss. Phi Delta Kappan, 92, 64-67.

Ladd, H. F. (2007). Holding schools accountable revisited. APPAM-Spencer Foundation Lecture. Retrieved October 24, 2011, from http://www.APPAM.org.

Ladd, H. F. (2010). Education inspectorate systems in New Zealand and the Netherlands. Education Finance and Policy, 5, 378-392.

Ladd, H. F., \& Loeb, S. (in press). The challenges of measuring school quality: Implications for educational equity. In D. Allen \& R. Reich (Eds.), Education, democracy and justice. Chicago, IL: University of Chicago Press.

Ladd, H. F., Muschkin, C., \& Dodge, K. (2011). From birth to school: Early childhood programs and third grade outcomes in North Carolina. Paper presented at the fall 2011 meetings of the Association for Public Policy Analysis and Management. Washington, DC.

Mervis, J. (2011). Giving children a head start is possible-But it's not easy. Science, 333, 956-957.

Noe, C. (2004). Bush decries democrats' soft bigotry of low expectations. Retrieved October 25, 2011, from http://newsmax.com.

O'Day, J. A., \& Smith, M. S. (1993). School reform and equal opportunity: An introduction to the education symposium. Stanford Law \& Policy Review, 10, 15-20.

Organization for Economic Co-operation and Development. (2010). PISA 2009 results: Overcoming social background-Equity in learning opportunities and outcomes (Vol. II). Paris: Author. 
Phillips, M. (2011). Parenting, time use, and disparities in academic outcomes. In G. Duncan \& R. Murnane (Eds.), Whither opportunity? Rising income inequality and the uncertain life chances of low-income children (pp. 207-228). New York: Russell Sage Foundation.

Raudenbush, S. W., Jean, M., \& Art, M. (2011). Year-by-year and cumulative impacts of attending a high-mobility elementary school on children's mathematics achievement in Chicago, 1995 to 2005. In G. Duncan \& R. Murnane (Eds.), Whither opportunity? Rising inequality and the uncertain life chances of low-income children (pp. 359-376). New York City: Russell Sage.

Ravitch, D. (1995). National standards in American education: A citizen's guide. Washington, DC: Brookings Institution.

Raymond, M. (2009). Multiple choice: Charter school performance in 16 states. Stanford, CA: Center for Research on Education Outcomes, Stanford University.

Reardon, S. (2011). The widening achievement gap between the rich and the poor: New evidence and possible explanations. In G. J. Duncan \& R. J. Murnane (Eds.), Whither opportunity? Rising inequality, schools and children's life chances (pp. 91-116). New York: Russell Sage.

Reback, R. (2010). Schools' mental health services and young children's emotions, behavior and learning. Journal of Policy Analysis and Management, 29, 698-725.

Rones, M., \& Hoagwood, K. (2000). School-based mental health services: A research review. Clinical Child and Family Psychology Review, 3, 223-241.

Rothstein, R. (2004). Class and schools: Using social, economic and educational reform to close the black-white achievement gap. New York: Teachers' College.

Rothstein, R., Jacobsen, R., \& Wilder, T. (2008). Grading education: Getting accountability right. Washington, DC and New York: Economic Policy Institute and Teachers College Press.

Sahlberg, P. (2011). Finnish lessons: What can the world learn from educational change in Finland? New York: Teachers' College Press.

Springer, M., Ballou, D., Hamilton, L., Le, V., Lockwood, J. R., McCafffrey, D., Pepper, M., \& Stecher, B. (2010). Teacher pay for performance: Experimental evidence from the project on incentives in teaching. Nashville, TN: National Center on Performance Incentives at Vanderbilt University.

Tuttle, C. C., Teh, B., Nichols-Barrer, I., Gill, B. P., \& Gleason, P. (2010). Student characteristics and achievement in 22 KIPP middle schools. Washington, DC: Mathematica Policy Research. Retrieved October 25, 2011, from http://www.mathematicampr.com/ publications/pdfs/education/kipp_fnlrpt.pdf.

Tyler, J., Kane, T., Taylor, E., \& Wooten, A. (2011). Evaluating teacher effectiveness. Education Next, 11, 55-60.

UNICEF. (2010). The children left behind: A league table of inequality in child well-being in the world's rich countries. Innocenti Report Card 9. Florence, Italy: Innocenti Research Center.

Wilkinson, R., \& Pickett, K. (2010). The spirit level: Why greater equality makes societies stronger. New York: Bloomsbury Press. 